\title{
Determination of the structural, electronic, optoelectronic and thermodynamic properties of the methylxanthine molecules theophylline and theobromine
}

\author{
G. W. Ejuh ${ }^{1,2}$ - J. M. B. Ndjaka ${ }^{3}$ F. Tchangnwa Nya ${ }^{4}$ P. L. Ndukum ${ }^{5}$. C. Fonkem ${ }^{3}$. \\ Y. Tadjouteu Assatse ${ }^{3} \cdot$ R. A. Yossa Kamsi ${ }^{3}$
}

Received: 22 July 2020 / Accepted: 21 October 2020 / Published online: 1 November 2020 (c) Springer Science+Business Media, LLC, part of Springer Nature 2020

\begin{abstract}
RHF and DFT (wB97XD and B3LYP) methods with the $6-31++\mathrm{G}^{* *}$ basis set have been used to study structural, optoelectronic and thermodynamic properties of Theophylline and Theobromine. Dipole moment, average polarizability, anisotropy, first-order molecular hyperpolarizability, second-order molecular polarizability, HOMO and LOMO energy gap, molar refractivity, chemical hardness, chemical softness, electronic chemical potential, electronegativity, electrophilicity index, dielectric constant, electric susceptibility, refractive index and their thermodynamic properties have equally been calculated. To understand the vibrational analysis of our system, IR and RAMAN frequencies were calculated and described. Results reveal that molecules can have applications in linear and nonlinear optical devices, photonic devices and in molecular electronics. Equally, from dipole moment, average polarizability, anisotropy, first-order molecular hyperpolarizability, second-order molecular polarizability, HOMO and LOMO energy gap, molar refractivity, chemical hardness, chemical softness, electronic chemical potential, electronegativity, electrophilicity index and literature we suggest that Theophylline and Theobromine be consider as candidates for the treatment of COVID-19 and other respiratory diseases.
\end{abstract}

Keywords Methyxanthines · Optoelectronics · Molecular electronics $\cdot$ Thermodynamic properties $\cdot$ Linear and nonlinear optical properties

\section{Introduction}

Xanthine is a purine base found in most human body tissues and fluids and in other organisms. It is found in muscle tissue, liver spleen, pancreas and other organs as well as in the urine. It is formed during the degradation of adenosine monophosphate. It is created from

Electronic supplementary material The online version of this article (https://doi.org/10.1007/s 1108 2-020-02617-w) contains supplementary material, which is available to authorized users.

G. W. Ejuh

gehwilsonejuh@yahoo.fr

Extended author information available on the last page of the article 
guanine by guanine deaminase. Xanthine is produced naturally by both plants and animals. Methylxanthines are a unique class of drug that are derived from the purine base xanthine. They are a group of naturally occurring agents present as caffeine, theophylline and theobromine. Naturally, they occur in substances found in coffee, tea, chocolate and related foodstuffs (Waller and Sampson 2018). Caffeine is found in coffee beans tea leaves, cacao seeds, beans and kola nuts; theophylline is found in tea leaves; theobromine is found in cacao seeds and beans.

Methylxanthines have vasodilatory, anti-inflammatory and immunomodulatory actions. They increase chemoreceptor sensitivity as well as respiratory drive and can also improve diaphragmatic contractility (Poets 2018). They may help to prevent acute airway hyper responsiveness but do not appear to produce these effects chronically. However, lifethreatening events such as cardiac arrhythmia and seizures are associated with toxic levels of theophylline ( $>30 \mu \mathrm{g} / \mathrm{mL}$ ). As a result, methylxanthines are recommended only as adjunctive therapy with close monitoring of serum concentrations and cardiac monitoring (Heltzer and Spergel 2007). They have been used as the mainstay of pharmacologic treatment of apnea of prematurity for several decades (Gauda and Martin 2012). The methylxanthines theophylline and dyphylline are used in the treatment of airways obstruction caused by conditions such as asthma, chronic bronchitis, or emphysema, chronic obstructive pulmonary disease (COPD) (Beale 2011). Methylxanthines are nonselective inhibitors of phosphodiesterase and are said to have modest bronchodilator effect by this mechanism. Methylxanthines have been described as being able to act as mild psychostimulants (Lorist and Tops 2003; Nehlig 2010; Mitchell et al. 2011; Franco et al. 2012). Epidemiological studies related caffeine consumption in healthy subjects with prevention of neurodegenerative diseases (Nehlig 2010); in particular it seems that consumption of caffeinated coffee could prevent or defer the onset of $\mathrm{AD}$ and $\mathrm{PD}$ and has a decreased bronchodilating effect (Maia and De Mendonca 2002; Eskelinen et al. 2009; Costa et al. 2010). Methylxanthine mechanisms of action at the CNS level include antagonism of adenosine receptors, regulation of intracellular calcium levels, phosphodiesterase inhibition, and modulation of GABA receptor action (Franco et al. 2012).

Onatibia-Astibia et al. (2016) studied the potential of methylxanthine-based therapies in pediatric respiratory tract diseases. In their study, they presented the benefits of methylxanthine-based therapies in the apnea of prematurity and their translational potential in pediatric affections of the respiratory tract.

The mechanism of action of methyxanthines can be partially explain by the inhibition of the enzyme phosphodiesterase (PDE), which degrades cyclic nucleotide second messengers. Theophylline preferentially inhibits the isoenzymes PDE3 (which degrades cAMP and cyclic guanosine monophosphate [cGMP]) and PDE4 (which degrades cAMP). PDE3 is found in bronchial smooth muscle and PDE4 in several inflammatory cell types, including mast cells. The rise in intracellular cAMP in bronchial smooth muscle stimulates largeconductance voltage-gated $\mathrm{Ca}^{2+-}$ activated $\mathrm{K}^{+}$channels (BKCa) in the cell membrane, leading to cell hyperpolarization and muscle relaxation. However, theophylline only produces bronchodilation at relatively high plasma concentrations, and drugs that are more effective PDE inhibitors (such as dipyridamole) do not bronchodilate. Prolonging the duration of action of cyclic nucleotides may potentiate the action of $\beta 2$-adrenoceptor agonists and produce a synergistic dilator effect on bronchial smooth muscle. PDE inhibition also stimulates ciliary beat frequency in the airways and enhances water transport across the airway epithelium, which increases mucociliary clearance. In contrast, theophylline increases the force and rate of contraction of cardiac muscle through its effect on cAMP, but also causes arterial vasodilation by inhibiting the breakdown of cGMP (Poets 2018). 
Adenosine receptor antagonism may be relevant to some of the clinical effects of methylxanthines. Adenosine releases histamine and leukotrienes from mast cells, which results in the constriction of hyperresponsive airways in individuals with asthma. Theophylline is a potent antagonist at adenosine $\mathrm{A} 1, \mathrm{~A} 2$ and $\mathrm{A} 3$ receptors and may reduce bronchoconstriction by this mechanism. Adenosine receptor antagonism is responsible for central nervous system (CNS) stimulation, which improves mental performance and alertness, has positive inotropic and chronotropic effects on the heart, and in the kidney reduces tubular $\mathrm{Na}^{+}$reabsorption, which leads to natriuresis and diuresis (Poets 2018).

Our study is based on the methylxanthine Theophylline and Theobromine. Theophylline is the most commonly used methylxanthine. Theophylline is reported to improve inspiratory muscle function and have anti-inflammatory effects (Han and Lazarus 2016). It has been used for the treatment of asthma and is one of the most prescribed drugs because of its effectiveness and it is cheap (Onatibia-Astibia et al. 2016; Barnes 1996). Theophylline has demonstrated efficacy in attenuating the three cardinal features of asthma reversible airflow obstruction, airway hyper responsiveness, and airway inflammation. At lower serum concentrations, theophylline is a weak bronchodilator but retains its capacity as an immunomodulator, anti-inflammatory, and bronchoprotective drug but at high serum levels, toxic side effects are observed (Tilley 2011). It produces relaxation in the airways and of mascular smooth muscle thus decreasing the mean pulmomary arterial pressure (Rabe et al. 1995; Onatibia-Astibia et al. 2016). Theophylline and doxofylline synthetic xanthine derivative, have been recommended for the treatment of disorder caused by heavy air pollution in some Chinese cities which affects the lung function and exacerbates chronic obstructive pulmonary disease COPD with positive results and has proven efficacy (Akram et al. 2012). Theophylline has been tested for its therapeutic potential in the renal impairment following administration of nephrotoxic substances such as radio contrast media, cisplatin, calcineurin inhibitors or following ischemia-reperfusion injury since it enhanced intrarenal adenosine levels lead to reduced glomerular filtration rate in several pathological conditions (Osswald and Schnermann 2011).

Studies on Theobromine shows that it is present in high amounts in chocolate and cocoa and stimulates the central nervous system (CNS) in a lesser degree (Gates and Miners 1999). Nevertheless, theobromine consumption has health benefits, including protection of the enamel surface (Kargul et al. 2012) and cough suppression (Halfdanarson and Jatoi 2007). Growing evidence suggest that Theobromine may be a new and promising antitussive treatment for patients with either acute or chronic coughing (Tilley 2011). Furthermore, Theobromine has been shown to increase plasma HDL cholesterol and decrease plasma LDL cholesterol concentrations, conferring cardiovascular protection and reducing the risk of coronary heart disease (Khan et al. 2012; Neufingerl et al. 2013). Moreover, experiments in human and guinea-pig vagus nerve preparations have proven that Theobromine directly inhibits sensory afferent nerve activation (Usmani et al. 2005). It coraborate with the ability of methylxanthines to regulate the activation of human intermediateconductance $\mathrm{Ca} 2+$ activated potassium channels which are key in controlling afferent and efferent vagal activity as recently described (Fox et al. 1997; Shcroder et al. 2000). Theobromine acts as a uric acid crystallization inhibitor, with high clinical potential in the treatment and prevention of uric acid nephrolithiasis (Grases et al. 2014).

Experimental and theoretical studies have been carried out on these molecules to determine some of the properties of the molecules. An overview of the molecular spectroscopic on Theobromine and it related alkaloids has been carried by Tewari et al. 2012 (Tewari et al. 2012). In 2018, Bilkan study effects of solvent on the spectroscopic and structure properties of Theobromine (Bilkan 2018). In 2007, Bilkan used Hatree Fock and Density 
functional theory to study the effect of solvent on Theobromine (Bilkan 2017) while Ucun et al. carried out some quantum chemical calculations on the molecular structures and vibrational frequencies of Xanthine and its methyl derivatives (Ucun et al. 2007). Camiruaga et al. (2019) studied the influence of the relative position of the methyl substituent on the photophysics of theophylline and theobromine, which are structurally related to the DNA bases.

Nolasco et al. (2006) used a new computationally-assisted methodology, which accounts for the effects of intermolecular interactions in crystal, to study the assignment of Raman and infrared vibrational spectra at room temperature of crystalline caffeine, theobromine, and theophylline. In their studies, the vibrational shifts due to crystal packing interactions were evaluated from ab initio calculations for a set of suitable molecular pairs, using the B3LYP/6-31G* approach. Their proposed methodology provides an answer to existing demand for a reliable assignment of the vibrational spectra of these methylxanthines, and clarified several misleading assignments (Nolasco et al. 2006). Changenet-Barret in 2016, studied the Xanthines using Femtosecond Fluorescence Spectroscopy (Changenet-Barret et al. 2016). The objective of their study was to provide a first insight into the dynamical properties of xanthine fluorescence. The main investigation tool of their study was the femtosecond fluorescence spectroscopy using fluorescence up conversion, a technique which has widely proven to be valuable for the study of DNA bases whose fluorescence is extremely short-lived (Onidas et al. 2002; Gustavsson et al. 2010). They examined four monomethylated derivatives, Theophylline, Theobromine and five other methylated xanthines characterized by different methylation sites and various degrees of methylation. Furthermore, it has been shown that the self-association of Theophylline, Theobromine and other xanthine derivatives can give rise to four-stranded structures (Szolomájer et al. 2011; Paragi et al. 2011; Novotny et al. 2012; Novotny et al. 2014; Yurenko et al. 2014), which have attracted attention to their applications in the field of molecular electronics (Livshits et al. 2014).

In this regard, in order to understand the structural, electronic, optoelectronic, the thermodynamic properties, the pharmacokinetics and pharmacodynamics of these molecules, we determined the dipole moment, average polarizability, anisotropy, first molecular hyperpolarizability, molar refractivity, LUMO-HOMO energy band gap, ionization potential, electron affinity, Kohn-Sham HOMO-LUMO gap, work function, chemical hardness, chemical softness, electronic chemical potential, electronegativity, electrophilicity index, the partition coefficients, electric flied, polarization density, dielectric constant, displacement vector, electric susceptibility and refractive index of Theophylline and Theobromine. To the best of our knowledge, there are not enough studies in literature on the investigation of the structural, electronic, optoelectronic and thermodynamics properties of Theophylline and Theobromine.

\section{Methodology}

The optimized molecular structures, structural properties, vibrational frequencies thermochemical properties and electronic properties of theophylline and Theobromine were calculated using the Gaussian 09 quantum code (Frisch et al. 2009) and the Gauss view 5 visualization program (Dennington et al. 2008). Initially, the molecular structures were optimized using the RHF method with inclusion of the 3-21 basis set and further refine with the 6-311++G** basis set. Finally, the DFT was used with the wB97XD and 
B3LYP functional using by $6-311++\mathrm{G}^{* *}$ basis set. This is because the DFT method has proven to be one of the most accurate methods for the computation of the electronic structure of solids (Davydyuk et al. 2013; Ejuh et al. 2018a, b, 2020a, b; Fankam Fankam et al. 2020; Reshak et al. 2011, 2013, 2014a, b, c, 2017).

\section{Results and discussion}

\subsection{Optimized molecular structure and Geometric Parameters of the molecules Theophylline and Theobromine}

The optimized molecular structures of Theophylline and Theobromine are given in Fig. 1. The bond lengths of the molecules are reported in Table 1 while the bond angles are reported in Table 2. We observed that the bond lengths and bond angles of the molecules are approximately the same at RHF, wB97XD and B3LYP level of theories. The differences between the bond lengths is less than $0.02 \mathrm{~A}^{\circ}$ while the differences between the bond lengths is less 1 degree. We did not find any existing results of the bond length and bond angles for Theophylline in literature to compare our results with. From Table 1, we observed that the calculated $\mathrm{C}-\mathrm{N}, \mathrm{C}-\mathrm{C}$ and $\mathrm{N}-\mathrm{H}$ bond lengths of Theobromine are approximately equal to the theoretical and experimental bond length given in literature with the values of wB97XD being in better accord (Ford et al. 1998; Bilkan 2018). The experimental values are given in bracket. The differences between calculated and experimental bond length is less than $0.02 \AA$ and less than 1 degree for the bond angles. We noticed that the single $\mathrm{C} 1-\mathrm{C} 4$ bond length is shorter than the $\mathrm{C} 1-\mathrm{C} 2$ double bond length. The calculated $\mathrm{C}-\mathrm{N}$ bond lengths were in better accord with the experimental data given in literature (Ford et al. 1998; Bilkan 2018) compared to the other bond length. Similarly, the $\mathrm{C}-\mathrm{C}-\mathrm{C}, \mathrm{C}-\mathrm{N}-\mathrm{C} \mathrm{O}-\mathrm{C}-\mathrm{N}, \mathrm{N}-\mathrm{C}-\mathrm{N}$ and $\mathrm{C}-\mathrm{C}-\mathrm{O}$ bond angles of Theobromine are approximately equal to experimental values given in literature (Ford et al. 1998) compared to the theoretical values reported in literature (Bilkan 2018). This may be due to the difference in basis set.

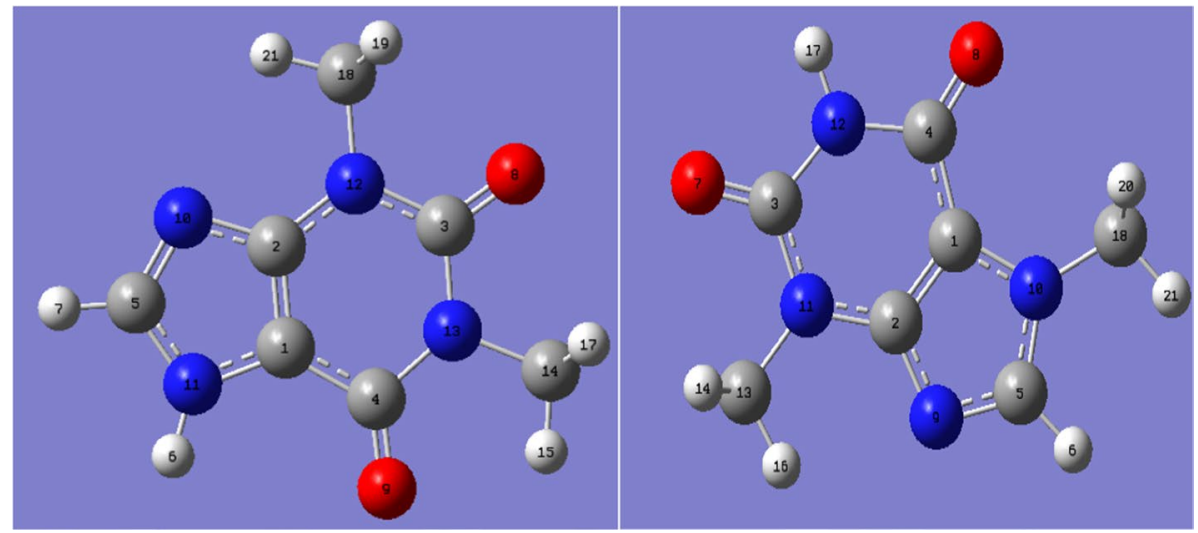

Fig. 1 Optimized molecule structure of Theophylline (left) and Theobromine (right) 


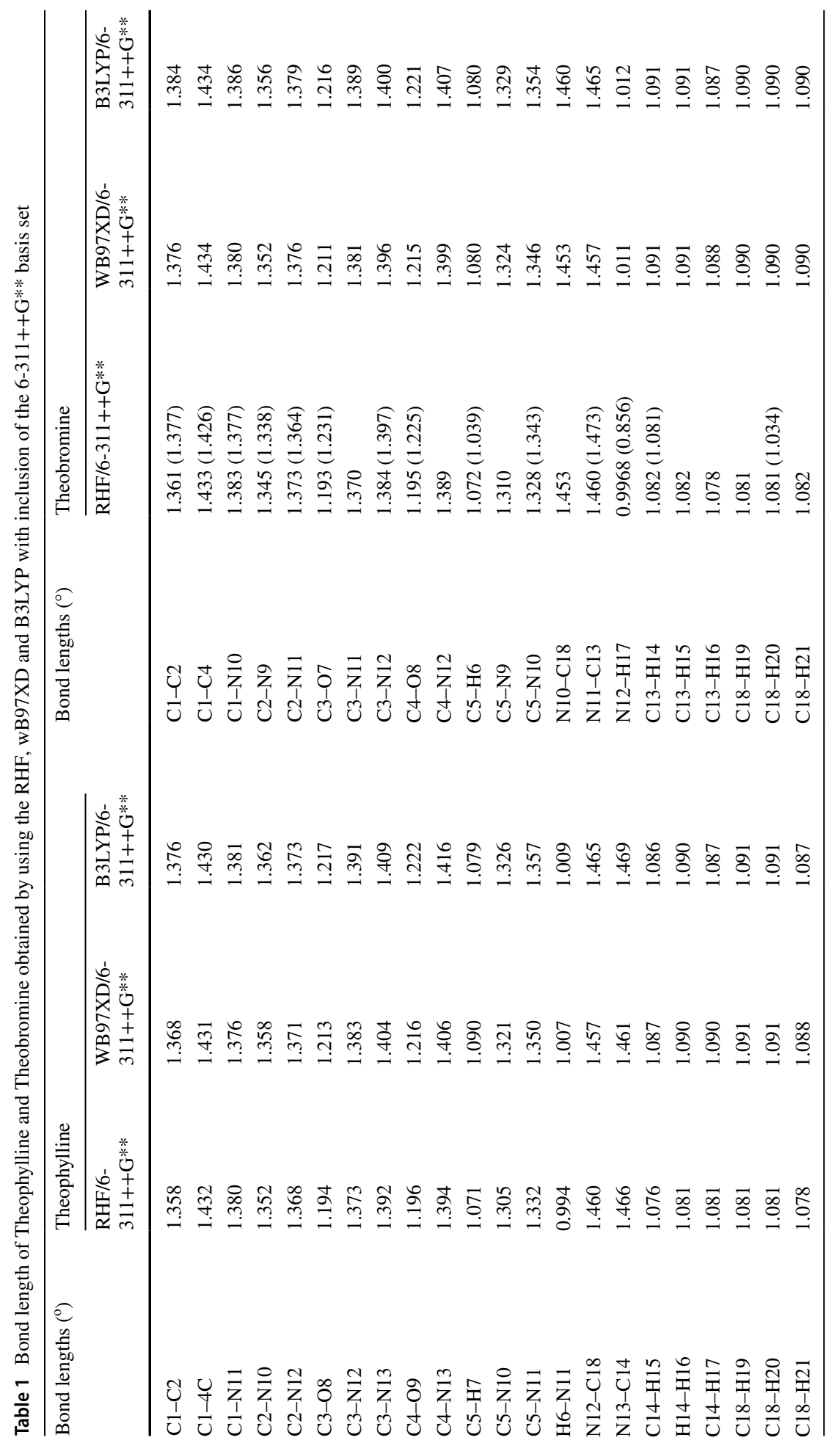




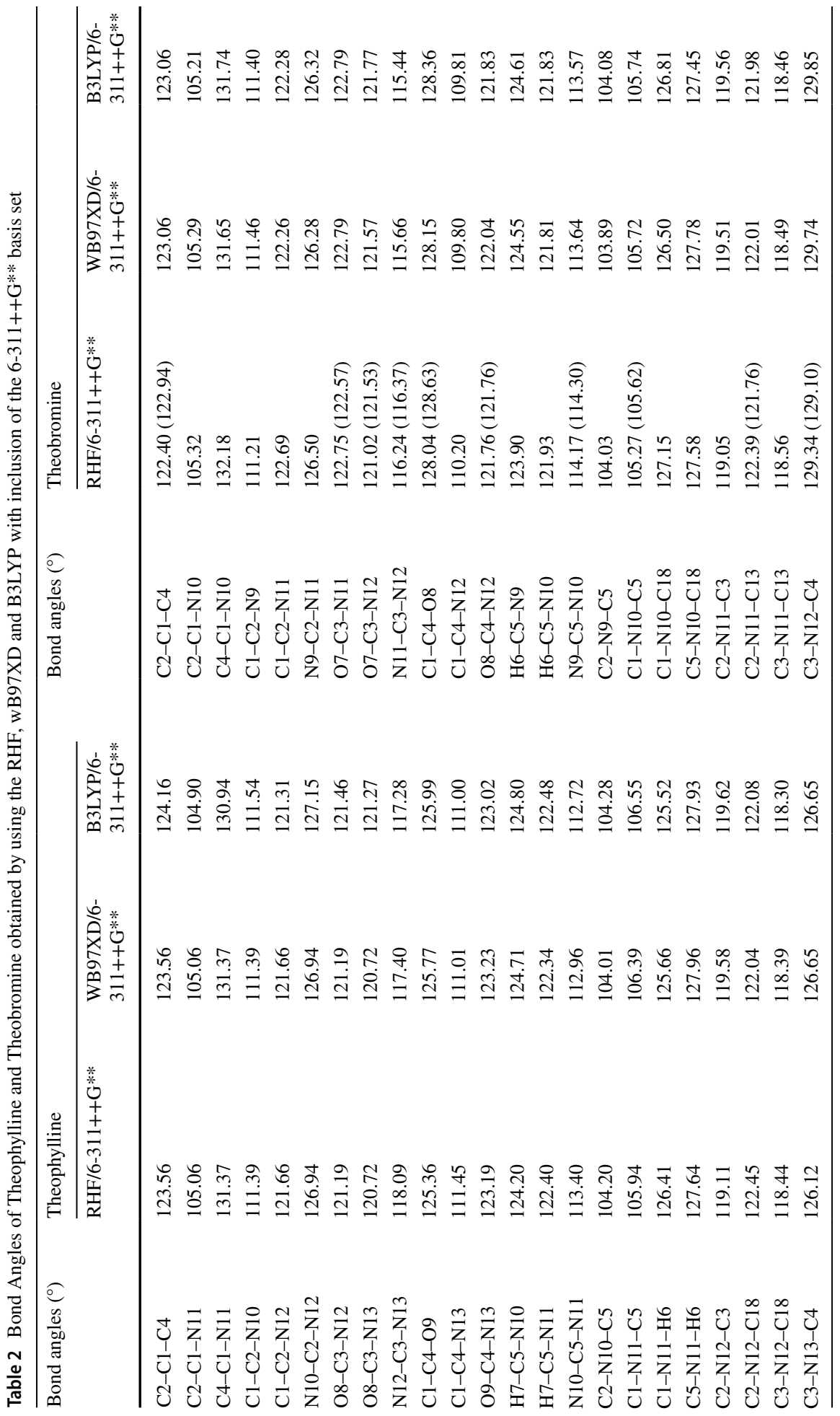




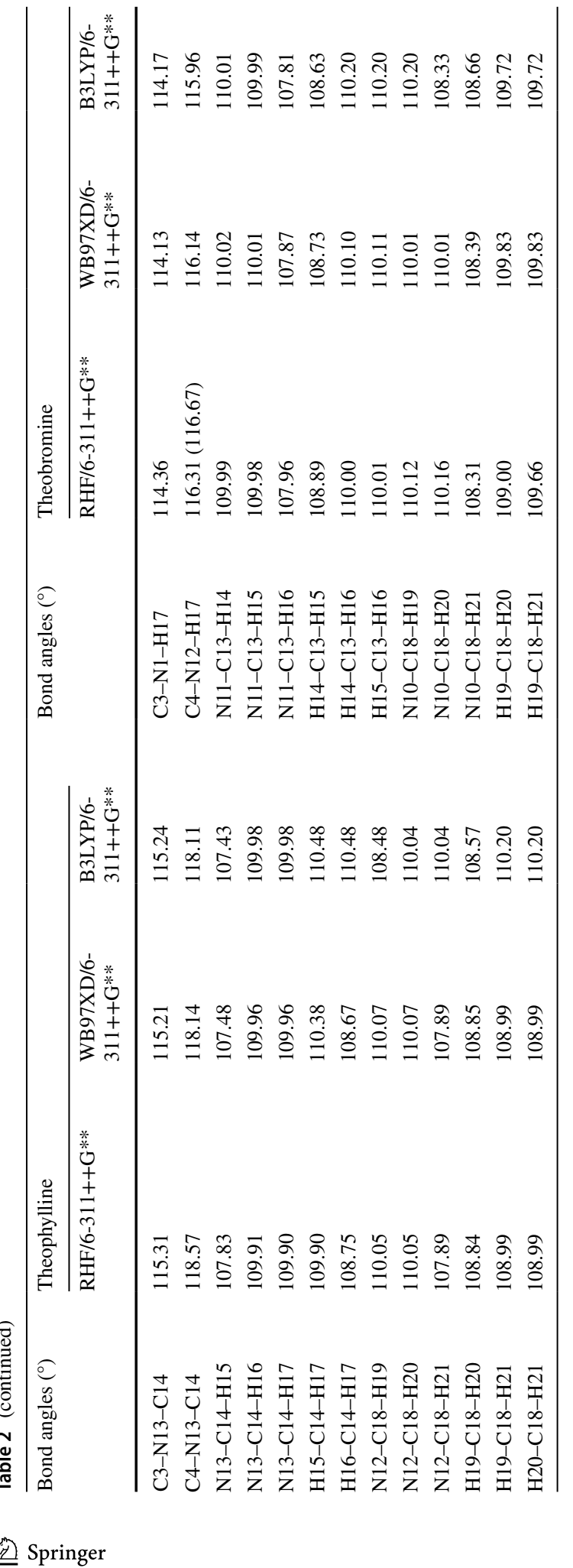




\subsection{Linear and nonlinear properties}

The linear and nonlinear properties such as dipole moment $\mu$, average polarizability $\langle\alpha\rangle$, anisotropy $\Delta \alpha$, first molecular hyperpolarizability $\beta_{m o l}$, second molecular hyperpolarizability $\gamma$, and molar refractivity $\mathrm{M}_{\mathrm{R}}$ of the methylxanthine Theophylline and Theobromine were determined and are reported in Table 3 . The study of polarizability and hyperpolarizability helps in understanding many physical phenomena (nonlinear optics, scattering and phenomena induced by interaction). Secondly, they are useful in molecular simulations and modeling of fundamental process and the search of new optical materials. Thirdly, they are useful in pharmacology where they are used as descriptors in quantitative structural analysis relationship (QSAR) and drug design (Murthy et al. 2007). Average polarizability and anisotropy are useful in polarizability studies and are of great experimental interest as reported in literature (Costa 2010). Hence the high values of $\langle\alpha\rangle$ and $\gamma$ permit us to have good information on the polarizability and gives room for experimentation so as to better understand the behavior of these molecules.

The polarizability of the molecules is closely related to the hardness and electronegativity and gives us information on the binding, reactivity and selectivity of the molecules. The large values of average polarizability, hardness and electronegativity of these molecules permit us to say that these molecules can easily bind and react with other molecules.

Table 3 Dipole moment $\mu$, average polarizability $\langle\alpha\rangle$, Anisotropy $\Delta \alpha$, first molecular hyperpolarizability $\beta_{\text {mol }}$, second molecular hyperpolarizability $\gamma$, and Molar refractivity $\mathrm{M}_{\mathrm{R}}$, LUMO-HOMO Energy band gap $\mathrm{Eg}$, Ionization potential IP, Electron affinity EA, Kohn-Sham HOMO-LUMO gap $E_{g}^{K S}$, work function $\mathrm{E}_{\mathrm{F}}$, chemical hardness $\omega$, chemical softness $\varsigma$, electronic chemical potential $\vartheta$, electronegativity $\phi$ electrophilicity index $\delta$ and the partition coefficients $\log \mathrm{P}$ of Theophylline and Theobromine molecules obtained at the RHF, wB97XD and B3LYP level of theory using the $6-311++\mathrm{G}^{* *}$ basis set

\begin{tabular}{|c|c|c|c|c|c|c|}
\hline \multirow[t]{2}{*}{ Parameter } & \multicolumn{3}{|c|}{ Theophylline } & \multicolumn{3}{|c|}{ Theobromine } \\
\hline & RHF & WB97XD & B3LYP & RHF & WB97XD & B3LYP \\
\hline$\mu(\mathrm{Cm}) \times 10^{-33}$ & 13.45 & 13.33 & 11.93 & 17.28 & 15.74 & 15.84 \\
\hline$\langle\alpha\rangle($ esu $) 10^{-24}$ & 14.85 & 15.78 & 14.57 & 14.71 & 21.04 & 28.30 \\
\hline$\Delta \alpha(\mathrm{esu}) 10^{-24}$ & 6.01 & 7.59 & 7.29 & 5.37 & 9.66 & 18.48 \\
\hline$\beta_{\mathrm{mol}}(\mathrm{esu}) 10^{-33}$ & 676.40 & 452.89 & 425.28 & 809.01 & 2993.78 & 1436.47 \\
\hline$\gamma(\mathrm{esu}) \times 10^{-33}$ & 7542.25 & 7614.72 & 7533.05 & 8038.06 & 8725.17 & 8646.88 \\
\hline $\mathrm{M}_{\mathrm{R}}(\mathrm{esu})$ & 37.47 & 39.81 & 36.76 & 37.11 & 53.08 & 71.40 \\
\hline $\mathrm{E}_{\text {LUMO }}(\mathrm{eV})$ & -4.37 & -4.42 & -4.45 & -4.43 & -4.81 & -4.81 \\
\hline $\mathrm{E}_{\text {Номо }}(\mathrm{eV})$ & -8.51 & -8.42 & -8.38 & -8.32 & -8.31 & -8.31 \\
\hline IP $(e V)$ & 8.51 & 8.42 & 8.38 & 8.32 & 8.31 & 8.31 \\
\hline $\mathrm{EA}(\mathrm{eV})$ & 4.37 & 4.42 & 4.45 & 4.43 & 4.81 & 4.81 \\
\hline $\mathrm{E}_{\mathrm{g}}(\mathrm{eV})$ & 4.20 & 4.00 & 3.93 & 3.89 & 3.50 & 3.50 \\
\hline$E_{g}^{K S}(\mathrm{eV})$ & 9.68 & 8.97 & 7.89 & 9.66 & 8.91 & 5.04 \\
\hline $\mathrm{E}_{\mathrm{F}}(\mathrm{eV})$ & -6.41 & -6.42 & -6.42 & -6.38 & -6.56 & -6.56 \\
\hline$\phi$ & 6.44 & 6.42 & 6.42 & 6.38 & 6.56 & 6.56 \\
\hline$\omega$ & 2.10 & 2.00 & 1.97 & 1.95 & 1.75 & 1.75 \\
\hline$\varsigma$ & 0.48 & 0.50 & 0.51 & 0.51 & 0.57 & 0.57 \\
\hline$\vartheta$ & -6.44 & -6.42 & -6.42 & -6.38 & -6.56 & -6.56 \\
\hline$\delta$ & 9.88 & 10.30 & 10.46 & 10.44 & 12.30 & 12.30 \\
\hline
\end{tabular}


Hence, we can say that these molecules can easily bind and react with the enzymes produce by the Corona virus. Polarizability is also related to molar refractivity, lipophilicity, molar volume and steric bulk as found in literature (Carrasco-velar et al. 2004; Padron et al. 2002). The molar refractivity which is also an important property in QSPR analysis was calculated from the expression $M_{R}=\frac{\left(\eta^{2}-1\right)\left(\eta^{2}+2\right)}{\rho} M w=1.333 \pi \mathrm{N}\langle\alpha\rangle$, where $\rho=$ density, $\eta=$ refractive index, $\mathrm{N}=$ Avogadro number and $\alpha=$ polarizability of the molecule. The values of the dipole moment tells us that this molecules are polar with Theobromine being more polar than Theophylline.

Equally, the large values of the dipole moment, average polarizability and hyperpolarizability of Theophylline and Theobromine permit us to conclude that the molecules have high binding affinity which implies they have good therapeutic index as documented in literature (Shi et al. 2000; Vrishnakumar and Nagalakshni 2008; Murthy et al. 2007; Kajzar et al. 2003; Costa 2010; Carrasco-velar et al. 2004; Padron et al. 2002; Kajzar et al. 2003; Ejuh et al. 2018a, b; Tadjouteu Assatse et al. 2019a, b; Veved et al. 2019; Fonkem et al. 2019, 2020; Yossa Kamsi et al. 2019). This is because polarizability, hyperpolarizability and hyper-order electric moments can be used to study the toxicity of drugs and polarizability is the main factor influencing the binding affinity of the drug. This can be explained by the fact that polarizability is a representation of molecular hydrophobicity ( $\mathrm{Gu}$ et al. 2007). Hence, the large values of the polarizability of the molecules show that the molecules have high binding affinity. Equally, studies have shown that binding to an active pocket of some receptor depends on the electronic structure of the ligand, with a significant contribution from dipole moment and polarizability (LaPointe and Weaver 2007). This may be due an electrostatic field generated by the receptor, and therefore would affect more strongly and interact with molecules which have a higher dipole moment or polarizability (Ferreira et al. 2009).

From the values of $\mu,\langle\alpha\rangle, \Delta \alpha, \beta_{m o l}, \mathrm{M}_{\mathrm{R}}, \gamma$ and from literature (Rabe et al. 1995; Barnes 1996; Maia and De Mendonca 2002; Lorist and Tops 2003; Heltzer and Spergel 2007; Eskelinen et al. 2009; Costa et al. 2010; Nehlig 2010; Beale 2011; Mitchell et al. 2011; Osswald and Schnermann 2011; Tilley 2011; Akram et al. 2012; Franco et al. 2012; Gauda and Martin 2012; Han and Lazarus 2016; Onatibia-Astibia et al. 2016; Poets 2018), we suggest that Theophylline and Theobromine may be consider as candidates for the treatment of COVID-19 since these molecules have high binding affinity, anti-inflammatory and immunomodulatory actions which is in line with CNN report of 23 March 2020. Based on this CNN News it was reported that some Chinese Medical Doctors have proposed that methylxanthines could be used for the treatment of COVID-19. This is due to the fact that these molecules can improve inspiratory muscle function, have anti-inflammatory effects and are being used for the treatment of airways obstruction caused by conditions such as asthma, chronic bronchitis, or emphysema, chronic obstructive pulmonary disease.

Equally the values of the $\beta_{m o l}$ and $\gamma$ of Theophylline and Theobromine is associated with the intramolecular charge transfer transfer resulting from the electronic cloud movement through the pi-conjugate from the electron donor to the electron acceptors which may result in linear and nonlinear optical activities (Shi et al. 2000; Vrishnakumar and Nagalakshni 2008). Hence, the molecules may equally have applications in linear and nonlinear optical active devices, photonic devices and in molecular electronics (Livshits et al. 2014). This is due to the fact that the value of the dipole moment, the average polarizability, molar refractivity and second hyperpolarizability of the molecules at the RHF and DFT levels are larger than the corresponding value of Urea as reported in literature (Tadjouteu Assatse et al. 2019b, Fonkem et al. 2019, 2020; Nkungli and Ghogomu 2016; Song and Farwell 
2004). Urea is one of a prototype molecule used for the purpose of comparison in the study of nonlinear optical (NLO) properties of molecular systems. Furthermore, the large values of the second-order molecular hyperpolarizability show that the molecules may have second harmonic generation, optical rectification, electro-pockel effect, electric induced second harmonic generation and the electro-optic Kerr effect. The values of $\mu,\langle\alpha\rangle, \Delta \alpha, \beta_{\text {mol }}$, $\mathrm{M}_{\mathrm{R}}, \gamma$ were determined using equations found in our previous works reported in literature (Ejuh et al. 2018a, b; Tadjouteu Assatse et al. 2019a; Veved et al. 2019; Fonkem et al. 2019, 2020; Yossa Kamsi et al. 2019; Veved et al. 2020).

\subsection{Electronic and chemical descriptors of the molecules}

The electronic and chemical descriptors of the molecules of the HOMO-LUMO Energy band gap $\mathrm{E}_{\mathrm{g}}$, Ionization potential IP, Electron affinity EA, Kohn-Sham HOMO-LUMO gap $E_{g}^{K S}$, work function $\mathrm{E}_{\mathrm{F}}$, chemical hardness $\omega$, chemical softness $\varsigma$, electronic chemical potential $\vartheta$, electronegativity $\phi$ and electrophilicity index $\delta$ of Theophylline and Theobromine molecules obtained at the RHF, wB97XD and B3LYP level of theory using the $6-311++\mathrm{G}^{* *}$ basis set are reported in Table 3 . This was done in order to identify the nature of the pharmacological properties of this molecules. The HOMO-LUMO molecular orbitals diagrams of the molecules Theophylline and Theobromine are shown in Fig. 2a, b respectively. The energy of the HOMO is directly related to the ionization potential $\left(\mathrm{IP}=-\mathrm{E}_{\mathrm{HOMO}}\right)$ and that of LUMO is linked directly to the electron affinity $\mathrm{EA}=-\mathrm{E}_{\mathrm{LUMO}}$ ). The HOMO and LUMO are very important quantum chemical parameters which are used to calculate many important parameters such as LUMO-HOMO Energy gap, Ionization potential, electron affinity, chemical potential, chemical hardness, chemical softness, electronegativity, electrophilicity index. These orbitals control the mode of the interaction of the drugs with other molecules such as the interactions between these drugs and their receptors. The $\mathrm{E}_{\mathrm{g}}$ gives us knowledge on the chemical activity of the molecules. HOMO-LUMO Energy band gap $\mathrm{E}_{\mathrm{g}}$ is used by the frontier electron density for the estimation of the most reactive sites in pi-electron systems and explain many types of reactions in conjugate systems (Shahidha et al. 2015). The $\mathrm{E}_{\mathrm{g}}$ values obtained from our studies eventually explains the charge transfer interactions taking place within Theophylline and Theobromine which is in line as reported in literature (Kadhum et al. 2012). The $\mathrm{E}_{\mathrm{g}}$ value of Theobromine obtained is less than the theoretical values reported in literature (Bilkan 2018) which may be due to difference in basis set. The $E_{g}$ values obtained at the B3LYP level for both molecules are smaller than those obtained at the RHF and wB97XD. The B3LYP functional has proven to give outstanding results for electronic structure calculation (Jamal et al. 2014; Reshak 2014a, b, c; Reshak and Auluck 2017; Ejuh et al. 2018a, b; Tadjouteu Assatse et al. 2019a; Veved et al. 2019; Fonkem et al. 2019, 2020; Yossa Kamsi et al. 2019; Veved et al. 2020). Equally, the large energy gap of the molecules tell us that there are many hydrophilic interactions that could facilitate the binding with the receptors. This suggests that such hydrophilic interactions considerably impact the binding affinity of these drugs to the receptors. The frontier molecular orbital of the molecules permit us to determine the chemical hardness $\omega=\frac{1}{2}\left(E_{L U M O}-E_{\text {HOMO }}\right)$. The small values of $\omega$ obtained from our results is an indication that the molecules are less stable since hardness is a measure of the stabilization energy. The values of $\omega$ correlate to the small $\mathrm{E}_{\mathrm{g}}$ values which correspond to easy deformation of the electron clouds of Theophylline and Theobromine making them very reactive. Results show that Theobromine is more reactive than Theophylline. From the $\mathrm{E}_{\mathrm{g}}$ and $\omega$ values obtained from our results, we can again say that 

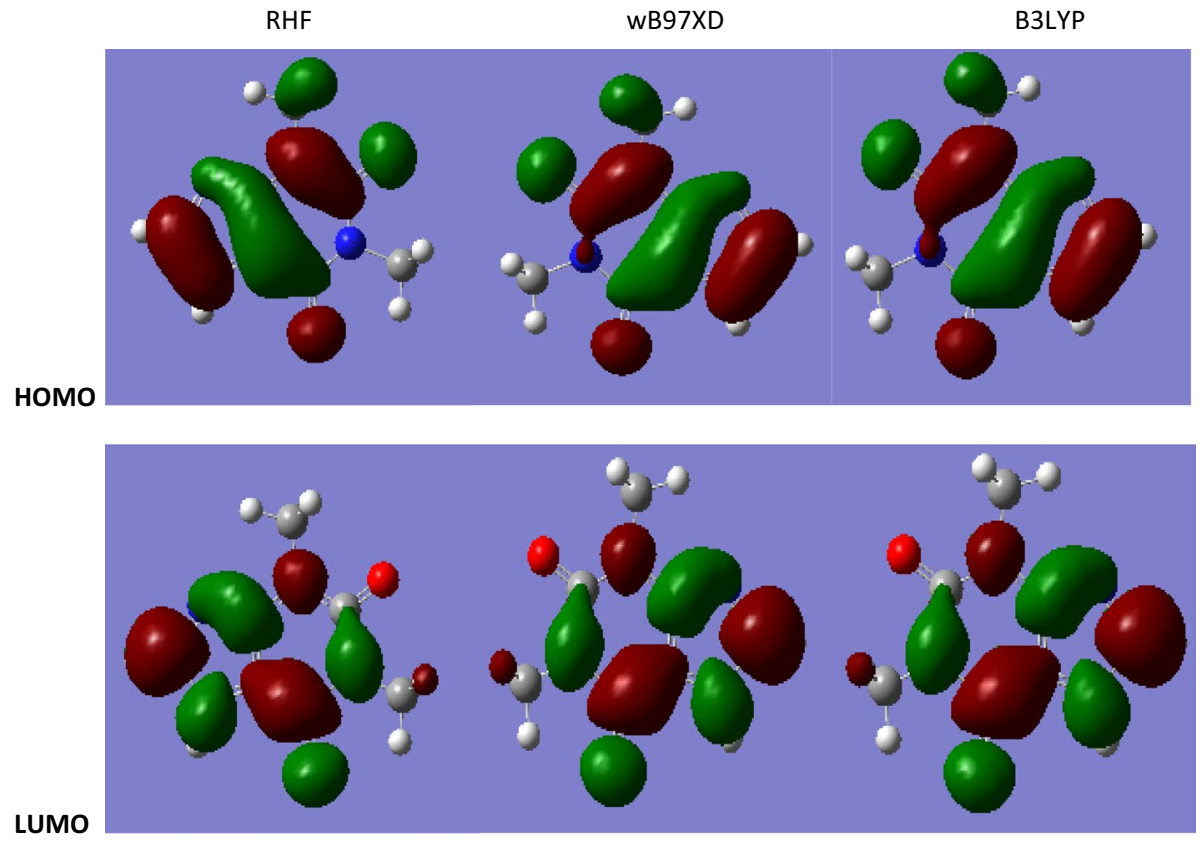

(a) HOMO-LUMO Molecular orbital diagram of Theophylline

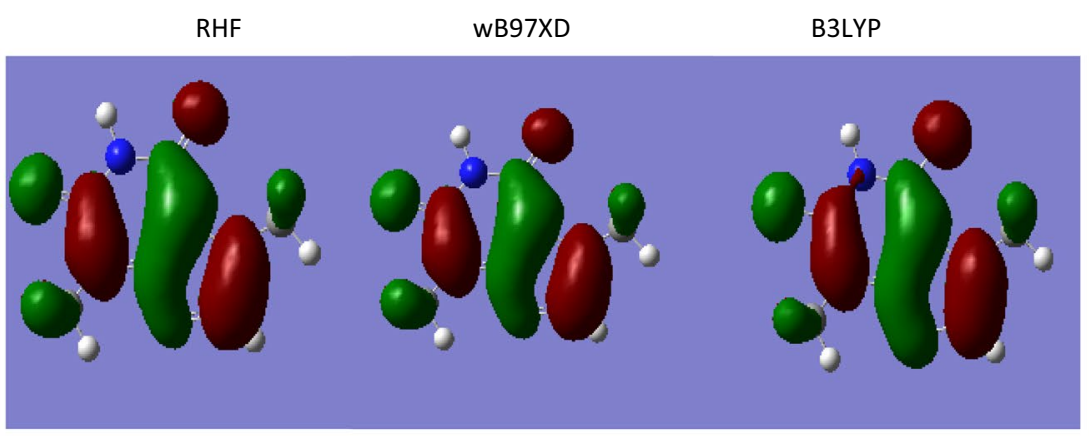

HOMO

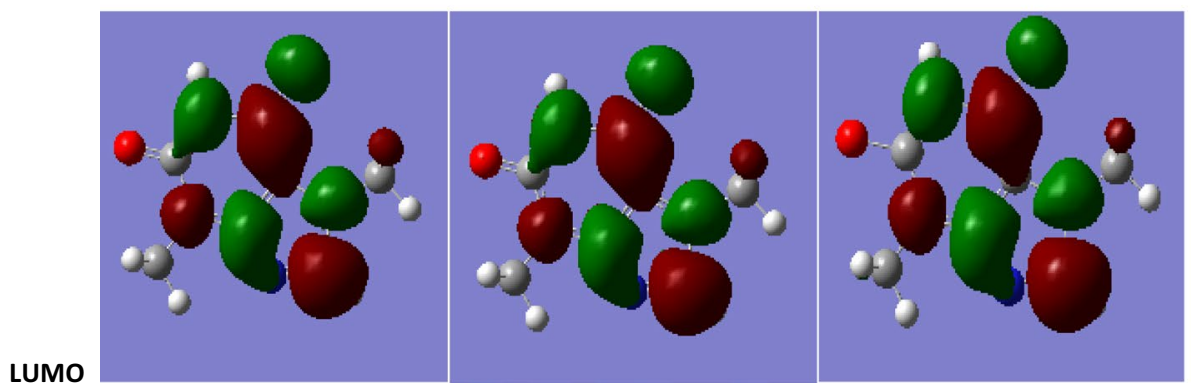

(b) HOMO-LUMO Molecular orbital diagram of Theobromine

Fig. 2 a HOMO-LUMO Molecular orbital diagram of Theophylline. b HOMO-LUMO Molecular orbital diagram of Theobromine 
the methylxanthine molecules Theophylline and Theobromine may easily react with other molecules and the enzymes produce by the Corona virus since the molecules are electronpair donors, even though Theophylline is a proton donor in most pharmaceutical systems (Beale 2011). Hence, we are tempted to say that Theophylline and Theobromine may be used as potential candidates for the treatment of COVID-19 which is a major concern of the WHO and whole World at large. The Kohn-Sham HOMO-LUMO gap $E_{g}^{K S}$ was determined from the occupied eigen values and the virtual eigen values given in the Gaussian output file. We observed that the $E_{g}^{K S}$ value for Theobromine was the same as the $\mathrm{E}_{\mathrm{g}}$.

The electronic chemical potential $\vartheta$ was determined from the expression $\vartheta=\frac{1}{2}\left(E_{L U M O}+E_{\text {HOMO }}\right)$. It describes the tendency of electrons to escape from a system in equilibrium. The larger the $\vartheta$ value, the less stable or more reactive is the molecule. Hence, the molecule Theobromine is more reactive than Theophylline. The electrophilicity index $\delta$ was calculated by combining the chemical hardness with the electronic chemical potential given by $\delta=\frac{\vartheta^{2}}{2 \omega}$. It measures the second-order energy of an electrophile when it gets saturated with electrons. It is a measure of the electrophilic power, just as in classical electrostatics, power $=\frac{V^{2}}{R}, \vartheta$ and $\omega$ serves the purpose of the potential and resistance R respectively. It correlates more with the electron affinity than with the electronegativity (Giju et al. 2005). From our results, Theobromine is a stronger electrophile than Theophylline which is in line with (Beale 2011).

The chemical softness which is inversely proportional to the chemical hardness of the molecules were equally determined. It is proportional to the magnitude of the electrical conductivity. Implies the large values of the softness of the molecules permit us to say that these molecules have high electrical conductivity. Hence, Theophylline and Theobromine can also be consider to have application in photovoltaic and electronic devices due to the large value of their chemical softness and small HOMO-LUMO band gap. The work function of each molecule was also determined from the Fermi energy $\mathrm{E}_{\mathrm{F}} E_{F}=E_{\text {HOMO }}+\frac{E_{g}}{2}$.

From the values of the partition coefficients $\log \mathrm{P}$ of the molecules documented in literature (Stanchev et al. 2013; Bilkan 2018), it is clear that the molecules are highly lipophilic. The parameter evaluated in our studies such as $\mathrm{E}_{\mathrm{g}}, \mu, \alpha, \beta, \gamma, \delta, \vartheta, \omega, \varsigma$ and $\phi$ are very useful and can be used to evaluate the chemical properties and possibilities for the interaction of Theophylline and Theobromine with biological molecules (enzymes and receptor) and their transport through the blood brain barrier and cell membranes. All of these parameters can be used as basis to study the QSAR of these molecule since they are closely related to pharmacokinetics and pharmacodynamics (Stanchev et al. 2013; Salihovic et al. 2014). The values of IP, AE and the $E_{g}(3.50-4.20 \mathrm{eV})$ of the molecules at the B3LYP level can be used to measure the redox potential of the molecules which is necessary for metabolism. The $\mathrm{E}_{\mathrm{g}}$ values at the B3LYP level are smaller while the values of $\mu, \delta \vartheta$ and $\omega$ are higher compared to the RHF and wB97XD values, and those reported in literature (Stanchev et al. 2013). This may be due to the used of polarized and diffuse basis sets as well as introduction of electron correlation contributions at the B3LYP level.

\subsection{Optoelectronic properties}

Optoelectronic properties such as: the average field $(\mathrm{E})$; the polarization density $(\mathrm{P})$; electric susceptibility $(\chi)$, the dielectric constant $\left(\varepsilon_{\mathrm{r}}\right)$, the displacement vector (D) and the refractive index $(\eta)$ are shown in Table 4. From our results, the value of the electric field $\mathrm{E}$ is of the order of $10^{6}$ with the RHF method giving the largest value for molecule. The values of the electric susceptibility, dielectric constant, displacement vector and 
Table 4 Volume $\mathrm{V}\left(\mathrm{m}^{3}\right)$, average electric field $\mathrm{E}\left(\mathrm{V} \mathrm{m}^{-1}\right)$, polarization density $\mathrm{P}\left(\mathrm{Cm}^{-2}\right)$, electric susceptibility $\chi$, dielectric constant $\varepsilon\left(\mathrm{C}^{2} \mathrm{~N}^{-1} \mathrm{~m}^{-2}\right)$, displacement vector $\mathrm{D}\left(\mathrm{C}^{2} \mathrm{~m}^{2} \mathrm{~J}^{-2}\right)$ and refractive index $\eta$

\begin{tabular}{lccccccc}
\hline Method & $\mathrm{V} \times 10^{-30} \mathrm{~m}^{3}$ & $\mathrm{E} \times 10^{6} \mathrm{Vm}^{-1}$ & $\mathrm{P} \times 10^{-4} \mathrm{Cm}^{-2}$ & $\chi$ & $\varepsilon_{(10)}^{-11}$ & $\eta$ & $\mathrm{D} \times 10^{-4}$ \\
\hline $\begin{array}{l}\text { Theophylline } \\
\text { RHF }\end{array}$ & 77.86 & 8.14 & 1.73 & 2.40 & 3.01 & 1.84 & 2.45 \\
wB97XD & 110.59 & 7.59 & 1.21 & 1.80 & 2.48 & 1.67 & 1.88 \\
B3LYP & 92.96 & 7.36 & 2.28 & 1.97 & 2.63 & 1.72 & 1.94 \\
Theobromine & & & & & & & \\
RHF & 100.55 & 10.56 & 1.72 & 1.84 & 2.52 & 1.69 & 2.6 \\
wB97XD & 94.82 & 6.73 & 1.66 & 2.79 & 3.36 & 2.09 & 2.26 \\
B3LYP & 88.12 & 6.68 & 1.80 & 3.04 & 3.58 & 2.14 & 2.39 \\
\hline
\end{tabular}

the refractive index obtained with wB97XD and B3LYP functional are slightly different and are greater than their corresponding values obtained with the RHF method with those of the B3LYP greater than those of wB97XD for Theobromine. For Theophylline, the value of the electric susceptibility, dielectric constant, displacement vector and the refractive index are higher at the RHF level compared to their corresponding values obtained with wB97XD and B3LYP functional, with wB97XD giving the smallest values. The differences between these parameters may certainly be due to the correlation effect of the electrons and the position of the methyl group in the molecules. These values were calculated using formulae given in literature (Ejuh et al. 2018a, b; Tadjouteu Assatse et al. 2019b; Veved et al. 2019; Fonkem et al. 2019, 2020; Yossa Kamsi et al. 2019; Veved et al. 2020). The large values of the average electric field, the electric susceptibility, refractive index and the small value of the dielectric constant of the molecules Theophylline and Theobromine permit us to say that these molecules have potential applications in the development of optoelectronic devices which is in line with the reference (Livshits et al. 2014).

\subsection{Thermochemical properties}

The zero-point vibrational energy, total electronic energy $\mathrm{E}_{\mathrm{tot}}$, the sum of electronic energy with zero-point correction $\mathrm{E}_{0}$, thermal energy correction, enthalpy energy correction, the thermal free energy, the thermal energy, entropy and the heat capacity have also been calculated, and the results are shown in Table 5. The values of the energies obtained with the B3LYP are slightly higher than those obtained with the wB97XD and those obtained with the wB97XD are slightly higher than those obtained with the RHF except for the ZPVE and the entropy where the reverse is observed. The observed differences is certainly due to the effect of correlation of the electrons. The values of the $\mathrm{E}_{\text {tot }}$ are slightly greater than those given in literature (Salihovic et al. 2014; Bilkan 2018) for both Theophylline and Theobromine. The $\mathrm{E}_{\mathrm{tot}}$ values of the molecules are approximately the same for same level of theory. This can be explained by the fact that the molecules have the same chemical formula but differ in their structural formulae due to the position of the $\mathrm{CH}_{3}$ group. The value of the ZPVE of Theobromine was higher than that given in literature while the values of heat capacity and the other energies were smaller (Bilkan 2018). 
Table 5 The total electronic energy $\mathrm{E}_{\text {tol }}$, Sum of electronic with the zero-point energy correction $\left(\mathrm{E}_{0}\right)$, thermal energy correction $\left(E_{1}\right)$, enthalpy correction $\left(E_{2}\right)$, free thermal energy $\left(E_{3}\right)$, are a.u., heat capacity $(\mathrm{Cv})$, entropy (S) and Zero-point vibrational energy (ZPVE) are calmol ${ }^{-1} \mathrm{~K}^{-1}$

\begin{tabular}{llllllllr}
\hline Method & $\mathrm{E}_{\text {tot }}$ & $\mathrm{E}_{0}$ & $\mathrm{E}_{1}$ & $\mathrm{E}_{2}$ & $\mathrm{E}_{3}$ & ZPVE x 10 & $\mathrm{C}_{\mathrm{V}}$ & \multicolumn{2}{l}{$\mathrm{S}$} \\
\hline Theophylline & & & & & & & \\
RHF & 637.469 & -637.297 & -637.286 & -637.285 & -637.334 & 108.220 & 38.937 & 102.579 \\
wB97XD & 641.035 & -640.620 & -640.612 & -640.611 & -640.655 & 103.493 & 33.248 & 94.430 \\
B3LYP & 641.244 & -640.833 & -640.825 & -640.824 & -640.867 & 102.347 & 31.875 & 89.039 \\
Theobromine & & & & & & & \\
RHF & 637.47 & -637.302 & -637.291 & -637.290 & -637.340 & 108.128 & 39.022 & 104.495 \\
wB97XD & 641.036 & -640.752 & -640.742 & -640.741 & -640.785 & 97.144 & 40.477 & 96.844 \\
B3LYP & 641.247 & -640.776 & -640.766 & -640.766 & -640.811 & 97.929 & 39.548 & 96.844 \\
\hline
\end{tabular}

\subsection{IR and Raman spectra}

The infrared and Raman spectra of Theophylline are given in Fig. 3a, b respectively while that of Theobromine are given in Fig. 4a, b respectively. Figures 3 and 4 show that the frequencies calculated at the RHF level are higher than those calculated at the wB97XD and B3LYP level. This may be due to the effect of electron correlation which is taken into consideration at the level of wB97XD and B3LYP functional. The IR and Raman spectra obtained are within the same range as that reported in literature for Theophylline (Nolasco et al. 2006; Balbuena et al. 2008; Gobbre et al. 2010; Tewari et al. 2012; Camiruaga et al. 2019) and Theobromine (Gunasekaran et al. 2004; Edwards et al. 2005; Nolasco et al. 2006; Ucun et al. 2007; Gobbre et al. 2010; Tewari et al. 2012; Bilkan 2017, 2018; Camiruaga et al. 2019) with the wB97XD and B3LYP closer to the experimental results. From our results, we observed that vibrational frequencies of some of the picks are slightly different from those reported in literature. This is due to the fact that our spectra were drawn from the vibrational frequencies data obtained from the output files which were not scaled (by 0.9668 for the $6-311++\mathrm{G}^{* *}$ basis set) so as to correct the differences between the calculated and experimental frequency values (Ejuh et al. 2011; Yurdakul and Bilkan 2015).

\section{Conclusion}

From our results, the $\mathrm{E}_{\mathrm{g}}, \mathrm{M}_{\mathrm{R}}, \mu,\left\langle\alpha>, \beta_{\text {mol }}, \gamma, \delta, \vartheta, \omega, \varsigma\right.$ and $\phi$ values obtained show that the methylxanthines Theophylline and Theobromine may easily react with other molecules and the enzymes produce by the Corona virus since the molecules are electron-pair donors, even though Theophylline is a proton donor in most pharmaceutical systems. Also from our results and from literature, we suggest that Theophylline and Theobromine may be consider as candidates for the treatment of COVID-19 which is in line with CNN report of 23 March 2020. Hence, we are proposing that trails should be carry out on the synthesis of Theophylline, Theobromine and other Xanthine derivatives to confirm if actually they may be used as potential candidates for the treatment of COVID-19 which is a major concern of the WHO and the whole World at large. 


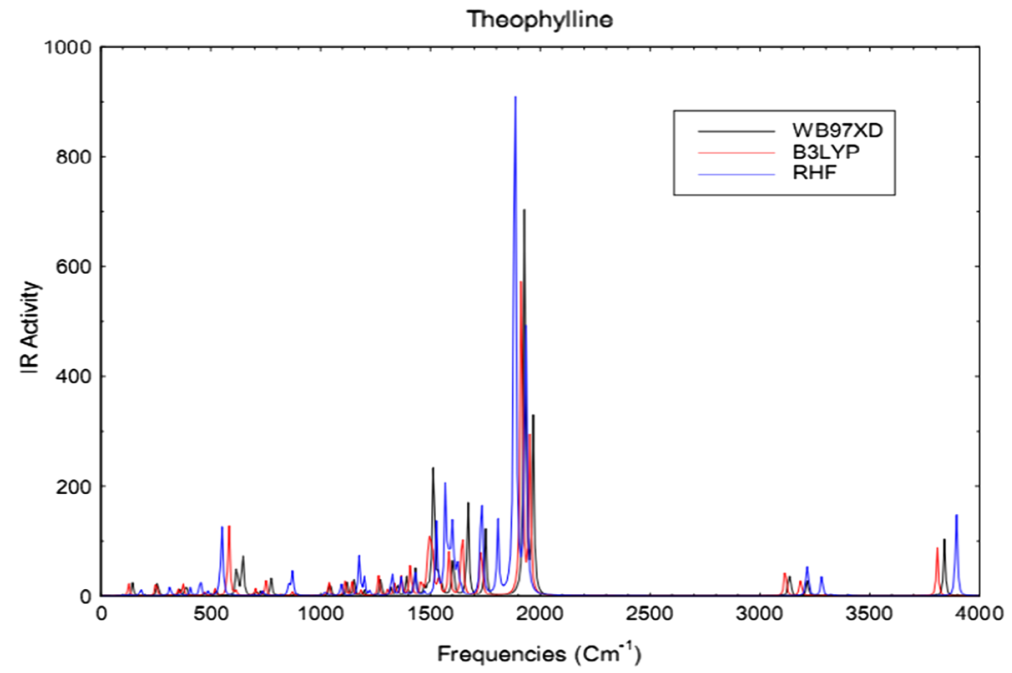

(a) RHF, wB97XD and B3LYP IR Spectrum of Theophylline

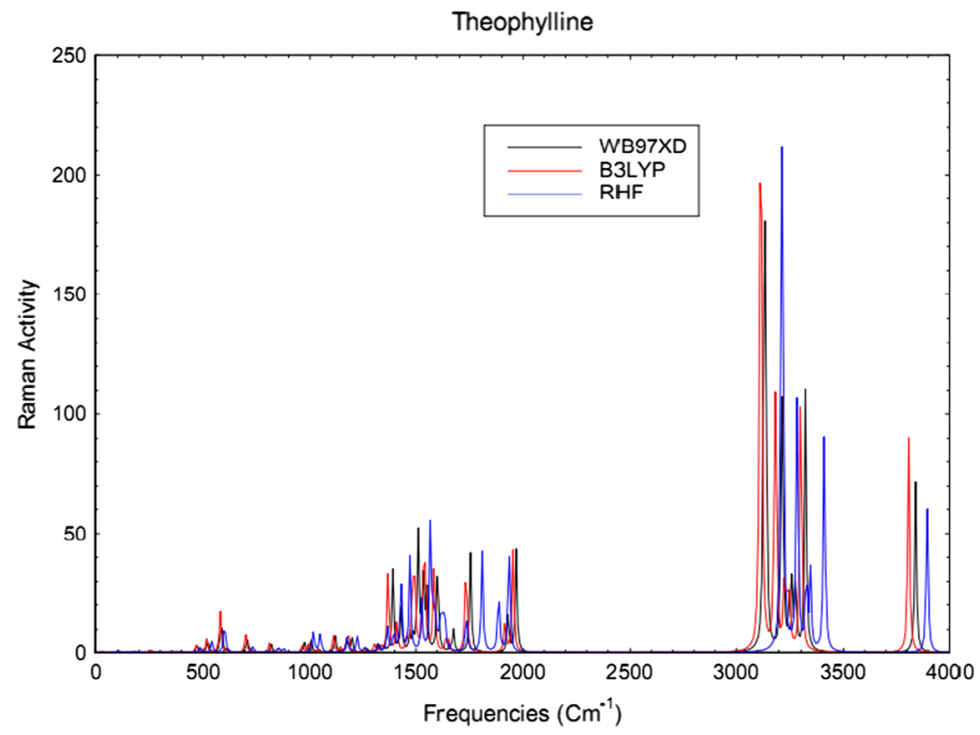

(b) RHF, wB97XD and B3LYP Raman spectra of Theophylline

Fig. 3 a RHF, wB97XD and B3LYP IR Spectrum of Theophylline. b RHF, wB97XD and B3LYP Raman spectra of Theophylline

Equally, the large values of the average electric field, the electric susceptibility, refractive index and the small value of the dielectric constant of the molecules Theophylline and Theobromine permit us to say that these molecules have potential applications in the development of optoelectronic devices which is in line with literature report.

Moreover, the values of the $\beta_{m o l}$ and $\gamma$ of Theophylline and Theobromine is associated with the intramolecular charge transfer resulting from the electronic cloud movement 


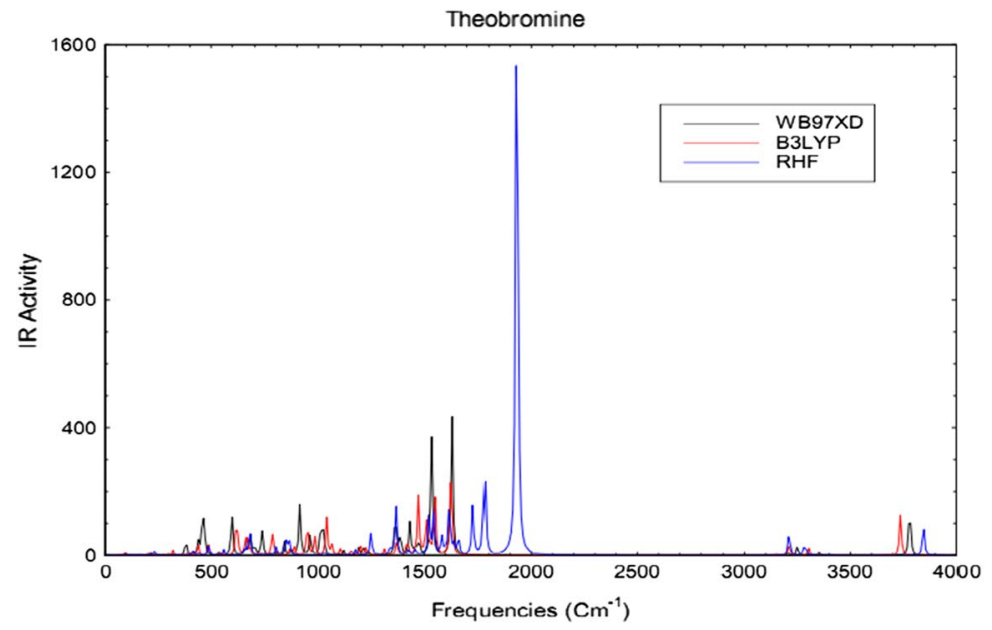

(a) RHF, wB97XD and B3LYP IR Spectrum of Theophylline

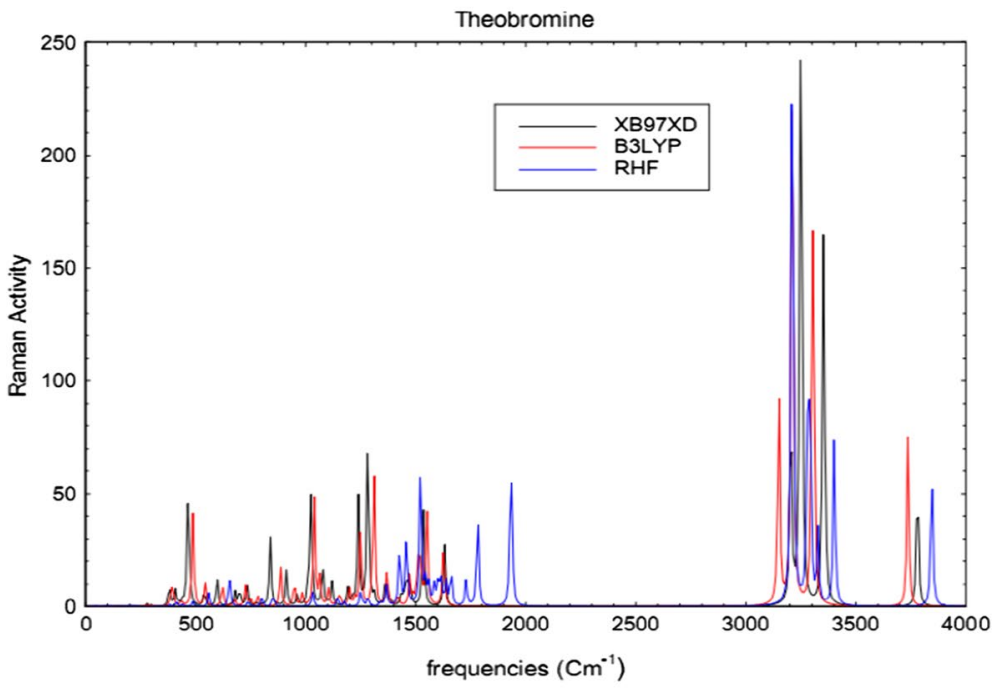

(b) RHF, wB97XD and B3LYP Raman spectra of Theobromine

Fig. 4 a RHF, wB97XD and B3LYP IR Spectrum of Theophylline. b RHF, wB97XD and B3LYP Raman spectra of Theobromine

through the pi-conjugate from the electron donor to the electron acceptors which may result in linear and nonlinear optical activities. Hence, the molecules may equally have applications in linear and nonlinear optical active devices, photonic devices and in molecular electronics.

Furthermore, the large values of the second-order molecular hyperpolarizability show that the molecules may have second harmonic generation, optical rectification, electro-pockel effect, electric induced second harmonic generation and the electro-optic Kerr effect. 
Acknowledgements We are thankful to the Council of Scientific and Industrial Research (CSIR), India for financial support through Emeritus Professor scheme (Grant No21(0582)/03/EMR-II) to late Prof. A.N. Singh of the Physics Department, Bahamas Hindu University, India which enabled him to purchase the Gaussian Software. We are most grateful to Late Emeritus Prof. A.N. Singh for donating this software to Prof. G. W. Ejuh.

\section{Compliance with ethical standards}

Conflict of interest The authors declare that there is no conflict of interest as concern this article.

\section{References}

Akram, M.F., Nasiruddin, M., Ahmad, Z., Ali Khan, R.: Doxofylline and theophylline: a comparative clinical study. J. Clin. Diagn Res. 6, 1681-1684 (2012)

Balbuena, P.B., Blocker, W., Dudek, R.M., Cabrales-Navarro, F.A., Hirusit, P.: Vibrational spectra of anhydrous and monohydrated caffeine and theophylline molecules and crystals. J. Phys. Chem. A 112(41), 10210-10219 (2008)

Barnes, P.J.: Pathophysiology of asthma. Br. J. Clin. Pharmacol. 42, 3-10 (1996)

Beale Jr., J.M.: Central nervous system stimulants. Wilson and Gisvold's Textb. Org. Med. Pharmaceut. Chem. 1, 505-506 (2011)

Bilkan, M.T.: Experimental and theoretical studies on theobromine and theobromine-water complexes. Aku J Sci Eng 18, 0111106 (2018)

Bilkan, M.T.: Structural and spectroscopic studies on dimerization and solvent-ligand complexes of Theobromine. J. Mol. J. Mol. Liq. 238, 523-532 (2017)

Camiruaga, A., Usabiaga, I., D’mello, V.C., García, G.A., Wategaonkar, S., Fernández, J.A.: Revisiting the spectroscopy of xanthine derivatives: theobromine and theophylline. Phys. Chem. Chem. Phys. 21, 26430-26437 (2019)

Carrasco-velar, R., Padron, J.A., Galvez, J.: Definition of a novel atomic index for QSAR: the refractotopological state. J. Pharmaceut. Sci. 7, 19-26 (2004)

Changenet-Barret, P., Kovács, L., Markovitsi, D., Gustavsson, T.: Xanthines studied via femtosecond fluorescence spectroscopy. Molecules 21(12), 1668 (2016). https://doi.org/10.3390/molecules2 1121668

Costa, M.F.: A theoretical study of 1,4-bis (3-carboxy-3-oxo-prop-1-enyl) benzene I. Ciencias Exatas e Tecnologicas, Londrina 31(1), 31-36 (2010)

Costa, D.A., Ferreira, G.D.G., Araujo, C.V., Colodo, J.C.N., Moreira, G.R., Figueiredo, M.R.P.: Intake and digestibility of diets with levels of palm kernel cake in sheep. Rev. Bras. Saude Prod. Anim. 11(3), 783-792 (2010)

Dennington, D.R., Keith, T., Miller J.: GaussView, Version 5.0.8, Semichem Inc., Shawnee Mission KS (2008)

Edwards, H.G.M., Villar, S.E.J., Oliveira, L.F.C., Hyaric, M.L.: Analytical Raman Spectroscopic study of cacao seeds and their chemical extracts. Anal. Chim. Acta 538, 175-180 (2005)

Ejuh, G.W., Fonkem, C., Tadjouteu Assatse, Y., Yossa Kamsi, R.A., Tchangnwa Nya, F., Ndukum, L.P., Ndjaka, J.M.B.: Study of the structural chemical descriptors and optoelectronic properties of the drugs hydroxychloroquine and azithromycin. Heliyon 6(8), 04647 (2020a)

Ejuh, G.W., TchangnwaNya, F., Djongyang, N., Ndjaka, J.M.B.: Study of electronic, optoelectronic, linear and nonlinear optical properties and UV-Vis Spectrum of Coronene and Coronene doped Chlorine. SN Appl. Sci. 2, 1247 (2020b). https://doi.org/10.1007/s42452-020-3028-1

Ejuh, G.W., TchangnwaNya, F., Djongyang, N., Ndjaka, J.M.B.: Study of some properties of quinone derivatives from quantum chemical calculations. Opt. Quant. Electron. 50(9), 336 (2018a). https://doi. org/10.1007/s11082-018-1603-0

Ejuh, G.W., Ottou Abe, M.T., Tchangwa Nya, F., Ndjaka, J.M.B.: Prediction of electronic structure, dielectric and thermodynamical properties of flurbiprofen by density functional theory calculation. Karbala Int. J. Mod. Sci. 4(1), 12-20 (2018b)

Ejuh, G.W., Ndjaka, J.M.B., Singh, A.N.: Study of the structures and Physico-chemical properties of the molecules Pyrimethamine and Sulfadoxine by ab initio and DFT methods. Can. J. Pure Appl. Sci. 5(2), $1591(2011)$ 
Eskelinen, M.H., Ngandu, T., Tuomilehto, J., Soininen, H., Kivipelto, M.: Midlife coffee and tea drinking and the risk of late-life dementia: a population-based CAIDE study. J. Alzheimers Dis. 16(1), 85-91 (2009)

Fankam Fankam, J.B., Ejuh, G.W., Tchangnwa Nya, F., Ndjaka, J.M.B.: Theoretical investigation of the molecular structure, vibrational spectra, thermodynamic and nonlinear optical properties of 4, 5-dibromo-2, 7dinitro- fluorescein. Opt. Quant. Electron. 52, 292 (2020). https://doi.org/10.1007/ s11082-020-02396-4

Ferreira, A.M., Krishnamurthy, M., Moore Ii, B.M., Finkelstein, D., Bashford, D.: Quantitative structure-activity relationship (QSAR) for a series of novel cannabinoid derivatives using descriptors derived from semi-empirical quantum-chemical calculations. Bioorg. Med. Chem. 17, 2598 (2009)

Fonkem, C., Ejuh, G.W., Tchangnwa Nya, F., Yossa Kamsi, R.A., Ndjaka, J.M.B.: Theoretical study of optoelectronic properties of the molecule 2-cyano-3- [4- (diphenylamino) phenyl] acrylic acid. J. Iran. Chem. Soc. 17, 533-543 (2019)

Fonkem, C., Ejuh, G.W., Tchangnwa Nya, F., Yossa Kamsi, R.A., Tadjouteu Assatse, Y., Ndjaka, J.M.B.: A density functional theory (DFT) study of the doping effect on 2-cyano-3- [4 (diphenylamino) phenyl] acrylic acid. Chin. J Phys. 63, 207-2012 (2020)

Ford, K.A., Ebusuzaki, Y., Boyle, P.D.: Methylxanthines. II. Anhydrous Theobromine. Crystallograhica C54, 1980-1983 (1998)

Fox, A.J., Barnes, P.J., Venkatesan, P., Belvisi, M.G.: Activation of large conductance potassium channels inhibits the afferent and efferent function of airway sensory nerves in the guinea pig. J. Clin. Invest. 99, 513-519 (1997)

Franco, L., Sanchez, C.L., Bravo, R., Rodriguez, A.B., Barriga, C., Romero, E., Cubero, J.: The sedative effect of non-alcoholic beer in healthy female nurses. PLoS One 7(7), e37290 (2012). https://doi. org/10.1371/journal.pone.0037290

Frisch, M.J., Trucks, G.W., Schlegel, H.B., Scuseria, G.E., Robb, M.A., Cheeseman, J.R., Scalmani G., Barone, V., Petersson, G.A., Nakatsuji, H., Li, X., Caricato, M., Marenich, A., Bloino, J., Janesko B.G., Gomperts, R., Mennucci, B., Hratchian, H.P., Ortiz, J.V., Izmaylov, A.F., Sonnenberg, J.L., Williams-Young, D., Ding, F., Lipparini, F., Egidi, F., Goings J., Peng, B., Petrone A., Henderson, T., Ranasinghe, D., Zakrzewski, V.G., Gao, J., Rega, N., Zheng, G., Liang, W., Hada M., Ehara, M., Toyota, K., Fukuda, R., Hasegawa J., Ishida M., Nakajima, T., Honda, Y., Kitao, O., Nakai, H., Vreven, T., Throssell, K., Montgomery, Jr. J.A., Peralta, J.E., Ogliaro, F., Bearpark, M., Heyd, J.J., Brothers, E., Kudin, K.N., Staroverov, V.N., Keith, T., Kobayashi, R., Normand, J., Raghavachari, K., Rendell, A., Burant, J.C., Iyengar, S.S., Tomasi J., Cossi, M., Millam J.M., Klene M., Adamo, C., Cammi, R., Ochterski, J.W., Martin, R.L., Morokuma, K., Farkas O., Foresman, J.B., Fox D.J.: Gaussian 09, Revision A.02. Gaussian Inc, Wallingford (2009)

Gates, S., Miners, J.O.: Cytochrome P450 isoform selectivity in human hepatic theobromine metabolism. Br. J. Clin. Pharmacol. 47, 299-305 (1999)

Gauda, E.B., Martin, R.J.: Avery's Diseases of the Newborn (Ninth Edition) (2012)

Giju, K.T., De Proft, F., Geerlings, P.: Comprehensive study of density functional theory based properties for group 14 atoms and functional groups, $-\mathrm{XY}_{3}\left(\mathrm{X}=\mathrm{C}, \mathrm{Si}, \mathrm{Ge}, \mathrm{Sn}, \mathrm{Pb}\right.$, element $114 ; \mathrm{Y}=\mathrm{CH}_{3}$. J. Phys. Chem. A 109, 2925 (2005)

Gobbre, V.V., Pinjari, R.V., Gejji, S.P.: Structure and normal vibration in xanthine and its methyl derivatives from first principle calculation. J. Mol. Struct. 960(1-3), 86-92 (2010)

Gu, C., Jiang, X., Ju, X., Yu, G., Bian, Y.: Qsars for the toxicity of polychlorinated dibenzofurans through Dft-calculated descriptors of polarizabilities, hyperpolarizabilities and hyper-order electric moments. Chemosphere 67, 1325 (2007)

Gunasekaran, S., Sankari, G., Ponnusamy, S.: Vibrational spectral investigation on xanthine and its derivatives theophylline, caffeine, theobromine. Spectrochim. Acta Mol. Biomol. Spectros. 61(12), 117-127 (2004)

Gustavsson, T., Improta, R., Markovitsi, D.: DNA/RNA: building blocks of life under UV irradiation. J. Phys. Chem. Lett. 1, 2025-2030 (2010)

Grases, F., Rodriguez, A., Costa-Bauza, A.: Theobromine inhibits uric acid crystallization: a potential application in the treatment of uric acid nephrolithiasis. PLoS ONE 9(10), 111184 (2014). https:// doi.org/10.1371/journal.pone.0111184

Halfdanarson, T.R., Jatoi, A.: Chocolate as a cough suppressant: rationale and justification for an upcoming clinical trial. Support Cancer Ther. 4, 119-122 (2007)

Han, M.K., Lazarus, S.C.: Murray and Nadel's Textbook. Respir. Med. (Sixth Edition) (2016)

Heltzer, M., Spergel, J. M.: "Asthma" in Comprehensive Pediatric Hospital Medicine. Editors, Zaoutis L. A., VW Chaing V. W. Elsevier Publishers, Philadelphia. Chapter 75: 463-481 (2007) 
Jamal, M., Kamali Sarvestani, N., Yazdani, A., Reshak, A.H.: Mechanical and thermodynamical properties of hexagonal compounds at optimized lattice parameters from two-dimensional search of the equation of state. RSC Adv. 4(101), 57903-57915 (2014)

Kadhum, A.A.H., Al-Amiery, A.A., Shikara, M., Mohamad, A.: Synthesis, structure elucidation and DFT studies of new thiadiazoles. Int. J. Phys. Sci. 6(29), 6692-6697 (2012)

Khan, N., Monagas, M., Andres-Lacueva, R., Casas, C., Urpi-Sarda, M., et al.: Regular consumption of cocoa powder with milk increases HDL cholesterol and reduces oxidized LDL levels in subjects at high-risk of cardiovascular disease. Nutr. Metab. Cardiovasc. Dis. 22, 1046-1053 (2012)

Kargul, B., Ozcan, M., Peker, S., Nakamoto, T., Simmons, W.B., et al.: Evaluation of human enamel surfaces treated with theobromine: a pilot study. Oral Health Prev. Dent. 10, 275-282 (2012)

Kajzar, F., Lee, K.S., Jen, A.K.Y.: Polymeric materials and their orientation techniques for second-order nonlinear optics. Polymer Sci. 161, 1-85 (2003)

LaPointe, S.M., Weaver, D.F.: A review of density functional theory quantum mechanics as applied to pharmaceutically relevant systems. Curr. Comput. Aided Drug Des. 3, 290 (2007)

Livshits, G.I., Stern, A., Rotem, D., Borovok, N., Eidelshtein, G., Migliore, A., Penzo, E., Wind, S.J., Di Felice, R., Skourtis, S.S., Cuevas, J.C., Gurevich, L., Kotlyar, A.B., Porath, D.: Long-range charge transport in single G-quadruplex DNA molecules. Nat. Nanotechnol. 9, 1040-1046 (2014)

Lorist, M.M., Tops, M.M.: Caffeine, fatigue, and cognition. Brain and congn. 53(1), 82-94 (2003)

Maia, L., De Mendonca, A.: Does caffeine intake protect from Alzheimer's disease? Eur. J. Neurol. 9(4), 377-382 (2002)

Mitchell, A.J., Chan, M., Bhatti, H., Halton, M., Grassi, L., Johansen, C., Meader, N.: Prevalence of depression, anxiety, and adjustment disorder in oncological, haematological, and palliative-care setting: a meta-analysis of 94 interview based studies. Lancet Oncol. 12(2), 160-174 (2011)

Murthy, V.R., Raghuram, D.V., Murthy, P.N.: Drug, dosage, activity, studies antimalarials by physical methods-II. Biomed. Inf. Publish. Group 2(1), 12-16 (2007)

Nehlig, A.: Is caffeine a cognitive enhancer? J. Alzheimer's Dis. 20, 85-94 (2010)

Neufingerl, N., Zebregs, Y.E., Schuring, E.A., Trautwein, E.A.: Effect of cocoa and theobromine consumption on serum HDL-cholesterol concentrations: a randomized controlled trial. Am. J. Clin. Nutr. 97, 1201-1209 (2013)

Nkungli, N.K., Ghogomu, J.N.: Concomitant efects of transition metal chelation and solvent polarity on the first molecular hyperpolarizability of 4-methoxyacetophenone thiosemicarbazone: a DFT study. J. Theoret. Chem. (2016). https://doi.org/10.1155/2016/7909576

Nolasco, M.M., Amado, A.M., Ribeiro-Claro, P.J.A.: Computationally-assisted approach to the vibrational spectra of molecular crystals: study of hydrogen-bonding and pseudo-polymorphism. Chem. Phys. Chem. 7, 2150-2161 (2006)

Novotny, J., Kulhanek, P., Marek, R.: Biocompatible xanthine-quadruplex scaffold for ion-transporting DNA channels. J. Phys. Chem. Lett. 3, 1788-1792 (2012)

Novotny, J., Yurenko, Y.P., Kulhanek, P., Marek, R.: Tailoring the properties of quadruplex nucleobases for biological and nanomaterial applications. Phys. Chem. Chem. Phys. 16, 15241-15248 (2014)

Onatibia-Astibia, A., Martinez-Pililla, E., Franco, R.: The potential of methylxanthine-based therapies in pediatric respiratory tract diseases. Respir. Med. 112, 1-9 (2016)

Onidas, D., Markovitsi, D., Marguet, S., Sharonov, A., Gustavsson, T.: Fluorescence properties of DNA nucleosides and nucleotides: a refined steady-state and femtosecond investigation. J. Phys. Chem. B 106, 11367-11374 (2002)

Osswald, H., Schnermann, J.: Methylxanthines and the kidney. Handb. Exp. Pharmacol. 200, 1 (2011). https ://doi.org/10.1007/978364213443217

Padron, J.A., Carrasco, R., Pellon, R.F.: Molecular descriptor based on a molar refractivity partition using Randic-type graph-theoretical invariant. J. Pharmaceut. Sci. 5, 258-266 (2002)

Paragi, G., Kovács, L., Kupihár, Z., Szolomájer, J., Penke, B., Fonseca Guerra, C., Bickelhaupt, F.M.: Neutral and positively charged new purine tetramer structures: a computational study of xanthine and uric acid derivatives. New J. Chem. 35, 119 (2011)

Poets, C.F.: Pediatric Respiratory Medicine. (Second Edition)

Rabe, K.F., Magnussen, H., Dent, G.: Theophylline and selective PDE inhibitors as bronchodilators and smooth muscle relaxants. Eur. Respir. J. 8, 637-642 (1995)

Reshak, A.H., Auluck, S.: The influence of oxygen vacancies on the linear and nonlinear optical properties of $\mathrm{Pb} 7 \mathrm{O}(\mathrm{OH}) 3(\mathrm{CO} 3) 3(\mathrm{BO} 3)$. RSC Adv. 7, 14752-14760 (2017)

Reshak, A.H.: Spin-polarized second harmonic generation from the antiferromagnetic CaCoSO single crystal. Scientific Reports 7, 46415 (2017). https://doi.org/10.1038/srep46415

Reshak, A.H.: Ab initio study of TaON, an active photocatalyst under visible light irradiation. Phys. Chem. Chem. Phys. 16(22), 10558-10565 (2014a) 
Reshak, A.H., Kogut, Y.M., Fedorchuk, A.O., Zamuruyeva, O.V., Myronchuk, G.L., Parasyuk, O.V., Kamarudin, H., Auluck, S., Plucinski, K.J., JiriBila, J.: Linear, non-linear optical susceptibilities and the hyperpolarizability of the mixed crystals $\mathrm{Ag}_{05} \mathrm{~Pb}_{175} \mathrm{Ge}\left(\mathrm{S}_{1-x} \mathrm{Se}_{x}\right)_{4}$ : experiment and theory. Phys. Chem. Chem. Phys. 15, 18979-18986 (2013)

Davydyuk, G.E., Khyzhun, O.Y., Reshak, A.H., Kamarudin, H., Myronchuk, G.L., Danylchuk, S.P., Fedorchuk, A.O., Piskach, L.V., Mozolyuk, MYu., Parasyuk, O.V.: Photoelectrical properties and the electronic structure of $\mathrm{Tl}_{1-x} \mathrm{In}_{1-x} \mathrm{Sn}_{x} \mathrm{Se}_{2}(x=0,0.1,0.2,0.25)$ single crystalline alloys. Phys. Chem. Chem. Phys. 15, 6965-6972 (2013)

Reshak, A.H., Stys, D., Auluck, S., Kityk, I.V.: Dispersion of linear and nonlinear optical susceptibilities and the hyperpolarizability of 3-methyl-4-phenyl-5-(2-pyridyl)-1,2,4-triazole. Phys. Chem. Chem. Phys. 13, 2945-2952 (2011)

Reshak, A.H.: Fe 2 MnSi x Ge 1-x: influence thermoelectric properties of varying the germanium content. RSC Adv. 4(74), 39565-39571 (2014b)

Reshak, A.H.: Thermoelectric properties for AA- and AB-stacking of a carbon nitride polymorph $\left(\mathrm{C}_{3} \mathrm{~N}_{4}\right)$. RSC Adv. 4, 63137-63142 (2014c)

Salihovic, M., Huseinovic, S., Spirtovic-Halilovic, S., Osmanovic, A., Dedic, A., Asimovic, Z., Zavrsnik, D.: DFT Study and Biological Activity of Some Methylxanthines Bullet. Chem. Technol. Bosnia Herzegovina 42, 31-36 (2014)

Shahidha, R., Al-Saadi, A.A., Muthu, S.: Vibrational spectroscopic studies, normal co-ordinate analysis, first order hyperpolarizability, HOMO-LUMO of midodrine by using density functional methods. Spectrochim. Acta Part A 134, 127-142 (2015)

Shcroder, R.L., Jensen, B.S., Strobaek, D., Olensen, S.P., Christophersen, P.: Activation of the human, intermediate-conductance, $\mathrm{Ca} 2 \mathrm{p}$ activated $\mathrm{Kp}$ channel by methylxanthines. Pflugers Arch. 440, 809-818 (2000)

Shi, Y., Zhang, C., Bechtel, J.H., Dalton, L.R., Robinson, B.H., Steier, W.H.: Low (sub-1-volt) halfwave voltage polymeric electro-optic modulators achieved by controlling chromophore shape. Science 288, 119-122 (2000)

Song, X., Farwell, S.O.: Pyrolysis gas chromatography atomic emission detection method for determination of N-containing components of humic and fulvic acids. J. Analyt. Appl. Pyrolysis 71(2), 901-915 (2004)

Stanchev, S., Mitkov, J., Georgieva, M., Zlatkov, A.: DFT study of the physicochemical characteristics and spectral behavior of new 8-substituted 1,3,7-trimethylxanthines. Int. J. Quant. Chem. 113, 1384-1393 (2013)

Szolomájer, J., Paragi, G., Batta, G., Guerra, C.F., Bickelhaupt, F.M., Kele, Z., Pádár, P., Kupihár, Z., Kovács, L.: 3-Substituted xanthines as promising candidates for quadruplex formation: computational, synthetic and analytical studies. New J. Chem. 35, 476 (2011)

Tadjouteu Assatse, Y., Ejuh, G.W., Tchoffo, F., Ndjaka, J.M.B.: DFT studies of nanomaterials designed by the functionalization of modified carboxylated carbon nanotubes with biguanide derivatives for nanomedical, nonlinear and electronic applications. Chin. J. Phys. 58, 253-262 (2019)

TadjouteuAssatse, Y., Ejuh, G.E., Yossa Kamsi, R.A., Tchofo, F., Ndjaka, J.M.B.: Theoretical studies of nanostructures modeled by the binding of Uracil derivatives to functionalized $(5,5)$ carbon naotubes. Chem. Phys. Lett. 731, 136602 (2019)

Tewari, B.B., Beaulieu-Houle, G., Larsen, A., Kengne-Momo, R., Auclair, K., Butler, I.S.: An overview of molecular spectroscopic studies on theobromine and related alkaloids. Applied Spectro. Rev. 47, 163-179 (2012)

Tilley, S.L.: Methylxanthines in asthma. Handb. Exp. Pharmacol. 200, 439-456 (2011)

Ucun, F., Sağlam, A., Güçlü, V.: Molecular structures and vibrational frequencies of xanthine and its methyl derivatives (caffeine and theobromine) by ab initio Hartree-Fock and density functional theory calculations. Spectrochimica Acta A 67, 342-349 (2007)

Usmani, O.S., Belvisi, M.G., Patel, H.J., Crispino, N., Birrell, M.A., Korbonits, M., et al.: Theobromine inhibits sensory nerve activation and cough. FASEB J. 19, 231-233 (2005)

Veved, A., Ejuh, G.W., Djongyang, N.: Effect of HfO2 on the dielectric, optoelectronic and energy harvesting properties of PVDF. Opt. Quant. Electro. 23(10), 1 (2019)

Veved, A., Ejuh, G.W., Djongyang, N.: Study of the optoelectronic and piezoelectric properties of ZrO2 doped PVDF from quantum chemistry calculations. Chin. J. Phys. 63, 213-219 (2020)

Vrishnakumar, V., Nagalakshni, R.: Studies on the first-order hyperpolarizability and terahertz generation in 3-nitroaniline. Phys. B 403, 1863-1869 (2008)

Waller, D.G., Sampson, A.P.: Medical Pharmacology and Therpeutics (Fifth Edition) (2018) 
Yossa Kamsi, R.A., Ejuh, G.W., Tadjouteu Assatse, Y., Tchoffo, F., Ndjaka, J.M.B.: Computational study of reactivity and solubility Rubescin D and $\mathrm{E}$ in gas phase and in solvent media using Hatre-Fock and DFT method. Chinese J. Phys. 60, 1-11 (2019)

Yurdakul, S., Bilkan, M.T.: Spectroscopic and structural properties of 2,2'-dipyridylamine and its palladium and platinum complexes. Opt. Spectro. 119(4), 603-619 (2015)

Yurenko, Y.P., Novotny, J., Sklenar, V., Marek, R.: Exploring non-covalent interactions in guanine- and xanthine-based model DNA quadruplex structures: a comprehensive quantum chemical approach. Phys. Chem. Chem. Phys. 16, 2072-2084 (2014)

Publisher's Note Springer Nature remains neutral with regard to jurisdictional claims in published maps and institutional affiliations.

\section{Affiliations}

\section{G. W. Ejuh ${ }^{1,2}$ - J. M. B. Ndjaka ${ }^{3}$. F. Tchangnwa Nya ${ }^{4}$ P. L. Ndukum ${ }^{5} \cdot$ C. Fonkem ${ }^{3}$. Y. Tadjouteu Assatse ${ }^{3}$ R. A. Yossa Kamsi ${ }^{3}$}

1 Department of Electrical and Electronic Engineering, National Higher Polytechnic Institute, University of Bamenda, P. O. Box 39, Bambili, Cameroon

2 Department of General and Scientific Studies, IUT-FV Bandjoun, University of Dschang, P.O. Box 134, Bandjoun, Cameroon

3 Department of Physics, Faculty of Science, University of Yaoundé I, P.O. Box 812, Yaounde, Cameroon

4 Department of Physics, Faculty of Science, University of Maroua, P.O. Box 814 Maroua, Cameroon

5 Department of Computer Engineering, National Higher Polytechnic Institute, University of Bamenda, P. O. Box 39, Bambili, Cameroon 